\title{
Mental Retardasyonlu Bir Çocuğun Resüsitasyonuna İlişkin Etik Karar Verme Süresi: Olgu Sunumu
}

\author{
Ethical Decision Making Time Regarding Resuscitation of a Child with Mental \\ Retardation: Case Report
}

\author{
Yasemin SÖKMEN ${ }^{1}$ A,B,C,D,E,F@ , Ayden ÇOBAN ${ }^{2}$ A,B,C,D,E,F,G \\ ${ }^{1}$ Ondokuz Mayıs Üniversitesi, Sağlık Bilimleri Fakültesi, Ebelik Bölümü, Samsun, Türkiye \\ ${ }^{2}$ Aydın Adnan Menderes Üniversitesi, Sağlık Bilimleri Fakültesi, Ebelik Bölümü. Aydın, Türkiye
}

ÖZ

\begin{abstract}
Resüsitasyon; pulmoner, kardiyak veya kardiyopulmoner arrest geliştiğinde yeterli solunum ve dolaşımı sağlamak için yapılan, bilgi ve deneyim gerektiren uygulamalardır. Bu uygulamada sağlik profesyonelleri tarafindan temel yaşam desteği ve ileri yaşam desteği hizmeti sunulmaktadır. Olgumuzda, 112 ile hastaneye sevk esnasında kardiyak arrest geçiren mental retardasyonlu çocuk bir devlet hastanesi acil birimine sevk edilmiştir. Acil birimde mavi kod girilen vakaya resüsitasyon müdahalesi esnasında anestezi uzmanının müdahaleyi bırakarak birimi terk etmesi etik karar verme süreci açısından tartışılmıştır.
\end{abstract}

Anahtar Kelimeler: Kardiyopulmoner resüsitasyon, Mental retardasyon, Çocuk, Mavi kod, Etik.

\section{ABSTRACT}

Resuscitation are applications that require knowledge and experience to ensure adequate breathing and circulation when pulmonary, cardiac or cardiopulmonary arrest develops. In this application, basic life support and advanced life support services are provided by healthcare professionals. In our case, a child with mental retardation who had cardiac arrest during the referral to the hospital with 112 was transferred to a public hospital emergency unit. It was discussed in terms of ethical decisionmaking process that the anesthesiologist abandoned the unit by interfering with the blue-code in the emergency unit during the resuscitation intervention.

Key Words: Cardiopulmonary resuscitation, Mental retardation, Child, Code blue, Ethic.

\section{GİRIŞ}

Kardiyovasküler sistem hastalıkları Dünya'da ve Ülkemizde önemli mortalite ve morbiditeye neden olmaktadır (1-3). Dünyada kalp ve damar hastalığından dolayı 2012 yılında 17,7 milyon kişi hayatını kaybederken, 2030 yılında 22,2 milyon olacağ tahmin edilmektedir (4). Amerika'da 2013 yılında, hastane içinde "ani kardiyak arrest" insidansı 209.000 olarak hesaplanmıştır (5). Ülkemizde ise Türkiye İstatistik Kurumu (TUIK) verilerine göre; 161.920 kişinin dolaşım sistemine bağlı nedenlerden hayatını kaybettiği bildirilmiştir (TUİK, 2018). Kardiyovasküler hastalıklara bağlı olarak ortaya çıkan ölümlerde ani dolaşım ve solunum durması söz konusudur. Böyle durumlarda resüsitasyon müdahalesi ile geri dönüşüm 
sağlanmaktadır. Resüsitasyon, pulmoner, kardiyak veya kardiyopulmoner arrest geliştiğinde yeterli solunum ve dolaşımı sağlamak için bilgi ve deneyim gerektiren uygulamalardır (7). Resüsitasyon ilk defa 1966 yllında National Academy of Sciences tarafindan standartize edilmiş, 1992 y1lında ise International Liaison Committee on Resuscitation tarafından rehber geliştirilmiştir (8-10).

Resüsitasyon, spontan dolaşımın dönmesini için temel yaşam desteği ve ileri yaşam desteği olmak üzere iki aşamada sürdürülmektedir. Temel yaşam desteği; durumun tanılaması, solunum ve göğüs kompresyonu kapsamaktadır. Öncelikle hastanın tepkisi "Nasılsın?" sorusu ile kontrol edilmektedir. Daha sonra bak, dinle, hisset yöntemiyle solunum varlı̆g araştırılmaktadır. Hastanın nabzı 10 sn içinde alınamadığı zaman göğüs kompresyonu uygulamasını içermektedir $(2,9,11,12)$. İleri yaşam desteği, resüsitasyon esnasında medikasyonun yanında cihaz kullanımını gerektiren komplike durumdur. İleri hava yolu açıklığının sağlanabilmesi için entübe edilmekte ve spontan dolaşıma dönüş olasılığını arttırmak için adrenalin uygulanmaktadır. Bu aşamada şoklanabilir ritmin saptanması halinde defibrilasyon kullanılmaktadır (9).

Mavi kod uygulaması; sağlık tesisinde tedavi görmekte olan hastaların resüsitasyon uygulamalarının tecrübeli bir ekip aracılığı ile mümkün olan en uygun şekilde gerçekleştirilmesini için düzenlenmiştir. Uygulama esasları 2011 yılında yayınlanan "Hasta ve Çalışan Güvenliğinin Sağlanmasına Dair Yönetmelik"'te belirlenmiştir. Sağlık kurumları bu yönetmelik doğrultusunda mavi kod uygulama esasları belirlemekte, mavi kod ekibi oluşturmakta ve gerekli malzemeleri temin etmektedir. Bu hizmet kapsamında tüm vatandaşlara 7/24 esasına göre hizmet sunmaktadır (13).

Sağlık hizmeti sunumda sağlık profesyonelleri etik olmayan durumlarla karşı karşıya kalabilmektedir. Bu aşamada seçim yaparken bilinçli ya da bilinçsiz karar verme modellerini kullanmaktadır. Etik karar verme modeli; bir endişenin belirlenmesinde, etik ilkelerin uygulanmasinda, alternatiflerin incelenmesinde, uygun eylemlere karar verilmesinde ve sonuçların değerlendirilmesinde yol göstermektedir. Bu modeller etik ikilemlerde kritik düşünme için çok değerlidir (14). Bu çalışma, kardiyak arrest sonrası resüsitasyon müdahalesi esnasında anestezi uzmanının müdahaleyi bırakarak birimi terk etmesi etik karar verme süreci açısından tartışılmıştır.

\section{OLGU SUNUMU}

Hasta A; 12 yaşında, mental retardasyonu olan bir çocuktur. Hasta A'nın evde genel durumu kötüleşmesi üzerine yakınları 112 ile irtibata geçmiştir. Nakil esnasında Hasta A kardiak arrest geçirmiş ve 112 ekibi tarafından temel yaşam desteği başlanmıştır. Mesai saatleri (08:00-17:00) içerisinde bir devlet hastanesi çocuk acil birimine Hasta A teslim edilmiştir.

Hasta A, devlet hastanesi acil biriminde resüsitasyon odasına alınmış ve mavi kod girilmiştir. Acil ekibinde o gün nöbetçi bulunan doktor, ebe ve hemşireler tarafından spontan solunum ve dolaşımı olmayan Hasta A'ya resüsitasyonu devam edilmiştir. Mavi kod ekibinde görevli olan anestezi uzmanı 2 dakika içerisinde resüsitasyon odasına ulaşmıştır. Anestezi uzmanı, hasta A'nın öyküsünü aldıktan sonra entübe etmek için iki defa girişim yapmış ama entübe edememiştir. Hasta A'nın engelli olduğunu öğrenen anestezi uzmanı “'zaten engelliymiş, toparlanamaz" ifadelerini kullanarak müdahaleyi bırakmış ve birimden ayrılmıştır. Bu esnada 
acil ekibi tarafindan hastaya yapılan ileri yaşam desteği sonucunda Hasta A'nın spontan kardiyak dolaşımı ve solunumu geri döndürülmüştür. Resüsitasyon odasında izlenimi devam eden Hasta A., yoğun bakım ünitesinde yer olmadığı için acil doktoru tarafından bir üniversite hastanesi yoğun bakım ünitesine sevk edilmiştir.

\section{TARTIŞMA}

Etik karar verme, sağlık alanında ortaya çıkan sorunların farkında olunması ve sorunlara profesyonel bir yaklaşım sergilenmesi açısından önemlidir (15). Yönt (16)'e göre etik karar vermede değerlendirme süreci; problemin saptanması, problemle ilgili bilgilerin kapsamlı bir şekilde veri toplanması, seçeneklerin belirlenmesi, eyleme geçme/uygulama ve sonuçların değerlendirilmesi olmak üzere beş aşamadan oluşmaktadır.

\section{Problemin-Sorunun Saptanması}

$\mathrm{Bu}$ olguda, kardiyak arrest sonrası resüsitasyon müdahalesi esnasında anestezi uzmanının müdahaleyi bırakarak birimi terk etmesi istenilmeyen durumdur.

\section{Problemle İlgili Bilgilerin Kapsamlı Bir Şekilde Veri Toplanması}

Anestezi uzmanının meslek and1, yasalar, yönetmelik, hekim etik kuralları ve kurumun idari amirinin verdiği yetki dahilinde vakaya müdahale etmesi gerekmektedir. Yalnız mavi kod uygulama esasında acil birimin mavi kod girmemesi yönünde bilgi bulunmaktadır. Bu durum ikileme yol açmaktadır.

Hasta Hakları Yönetmeliği, Acil Sağlık Hizmetleri Yönetmeliği, Sağlık Meslek Mensupları ile Sağlık Hizmetlerinde Çalışan Diğer Meslek Mensuplarının İş ve Görev Tanımlamalarına Dair Yönetmelik, Hekimlerin Mesleki Etik Kuralları, Hekimlik Andı, İdari amirin acile mavi kod girme yetkisi vermesi ile mavi kod uygulama sürecinde acil birimin mavi kod girmemesi yönünde bilgi bulunması çelişki yaratmaktadır.

Kararın o anda anestezi uzmanı ile ekip liderinin arasında, daha sonra kurum amirinin kanun/yönetmelik doğrultusunda netleştirmesi gerekmektedir. Anestezi uzmanının aldığı bu karardan en çok Hasta A'nın yaşamı olumsuz yönde etkilendiği düşünülmektedir. Hasta Haklarına Yönetmeliği'nde ise; "hasta, adalet ve hakkaniyet ilkeleri çerçevesinde sağlıklı yaşamanın teşvik edilmesine yönelik faaliyetler ve koruyucu sağlık hizmetleri dahil, sağlık hizmetlerinden ihtiyaçlarına uygun olarak faydalanma hakkına sahiptir." bildirilmektedir (17). Hekimin ise vicdani ve mesleki kanı, sır saklama yükümlülüğü, acil yardım, mesleki dayanışma, danışım ve ekip çalışması, hasta haklarına saygı gibi etik kodları kodları bulunmaktadir (18).

\section{Seçeneklerin Belirlenmesi}

Anestezi uzmanının aldığı bu karar en çok Hasta A'nın yaşamını etkilemekte iken herhangi bir faydası bulunmamaktadır. Ülkemizde resmi kurumlarda yayınlanan düzenlemelere göre;

- Anestezi uzmanının aldığ1 karar meslek etik kurallarından acil yardım, mesleki dayanışma, danışım ve ekip çalışması ve hasta haklarına saygı ilkelerine göre müdahale etmesi gerekmektedir. 
- Sağlık Bakanlığı'nca tabibin görevleri, “ortaya çıkan komplikasyonlarda uygun müdahaleyi yapar, gerektiğinde hastayı sevk eder. Diğer meslek mensupları tarafindan gerçekleştirilen tıbbi bakım ve uygulamaları planlar, izler ve denetler" olarak belirtildiği için müdahale etmesi beklenmektedir (19).

- Acil Sağlık Hizmetleri Yönetmeliği’nde belirtilen "24 saat kesintisiz hizmet veren kurum ve kuruluşlar bünyesinde bulunan acil servislerde, acil hasta ve yaralılar karşılanarak, ilk tıbbi müdahale ve tıbbi bakım yapılmalıdır." maddesine göre kuruma düşen görevler bulunmaktadır (20).

- Hasta Haklarına Yönetmeliği'nde ifade edilen "hasta, adalet ve hakkaniyet ilkeleri çerçevesinde sağlıklı yaşamanın teşvik edilmesine yönelik faaliyetler ve koruyucu sağlık hizmetleri dahil, sağlık hizmetlerinden ihtiyaçlarına uygun olarak faydalanma hakkına sahiptir." ibareye göre anestezi uzmanının müdahale etmesi gerekmektedir (17).

- Hekimlerin meslek etiği kuralları 25. madde'de “ hekim, ancak tıbbi bilgisini gerektiği gibi uygulayamayacağına karar verdiğinde ve hastasının başvurabileceği başka bir hekim bulunduğu durumlarda, hastanın bakımını ve tedavisini üstlenmeyebilir veya tedaviyi yarım bırakabilir. Tedaviyi bırakacak hekim, bu durumu ve hastanın sağlığının tehlikeye düşmeyeceği hastaya ve yakınlarına anlatılır ve onları tıbbi yardımla ilgili başka olanaklar konusunda bilgilendirilir. İkinci hekim bulunmadan hastasını bırakamaz. Hekim, tedaviyi üstlenen meslektaşına hasta hakkında bilgileri aktarmakla yükümlüdür.” ifadesine yer verilmiştir. Anestezi uzmanının aldığı karar meslek etik kurallarıyla örtüşmemektedir (18).

- $\quad$ Ayrıca yazılı olmayan sözlü gerçekleştirilen hekimlik andına bakıldığında "görevimle hastam arasına; yaş, hastalık ya da engellilik, inanç, etnik köken, cinsiyet, milliyet, politik düşünce, 1 rk, cinsel yönelim, toplumsal konum ya da başka herhangi bir özelliğin girmesine izin vermeyeceğime" yemini edilmektedir (21). Tüm hekimlerin mesleğe başlamadan önce gerçekleştirdiği meslek andına uygun davranmamıştır.

- Sağlık Bakanlığınca belirlenen mavi kod uygulamasında; "İdarece belirlenecek olan ve sıklıkla resüsitasyon uygulama gereksinimi oluşan acil servis, yoğun bakım ve ameliyathane gibi birimlerde mavi kod çağrısı verilmemekte, bu birimlerde tedavi gören hastalar için gerekli olan resüsitasyon müdahalelerin birim içinde gerçekleştirilmesi sağlanmaktadır." belirtilmektedir (13). Yalnız bu olayın gerçekleştiği hastanede idari amir olan başhekimi tarafından acil biriminin mavi kod vermesi ve anestezi tarafindan desteklenmesi kararı bulunmaktadır. Anestezi uzmanının aldığ 1 karar mavi kod uygulamasına göre sıkıntı yaratmazken, kurum amirinin verdiği karara uygun bir davranış değildir.

\section{Eyleme geçme/uygulama}

Olgumuzda anestezi uzmanının, yasalar, yönetmelikler, mesleki and, mesleki etik kod ve amirin yetkisi doğrultusunda acil biriminde mavi kod girilen durumlarda müdahale etmesi gerekmektedir. Bu olguda hekimin aldığı kararırın doğruluğu ya da yanlışlığı açısından tarafsız olarak resmi kurumlarca verilen kararlar doğrultusunda karar alınmıştır. 


\section{Sonuçların değerlendirilmesi}

Anestezi uzmanının, kardiak arrest gibi nedenlerden acil birimine getirilen hastalara mavi kod girildiğinde gerekli müdahale yapması yönünde karar verilmiştir. Süreç boyunca başka ikilemler ortaya çıkmamıştır. Alınan kararın hizmet kalitesini arttırması, mavi kod girilen hastalara daha kapsamlı hizmet verilmesi, acil ekip çalışma düzeninin sağlanması, olağanüstü durumlarda görev, yetki ve sorumlulukların belirlenmesi açısından olumlu yönde etkilemesi beklenmektedir.

\section{SONUÇ}

Sonuç olarak, kardiyak arrest sonrası acilde mavi kod girilen vakalarda anestezi uzmanının gerekli müdahalelere aktif katılması gerektiğine karar verilmiştir. Kardiyak arrest gibi hayati nedenlerle acil birimine getirilen hastaların nitelikli sağlık hizmeti alması, kurumun çalışanlara görev, yetki ve sorumluluklar hakkında eğitimler sunması, sağlık profesyonellerinin yasa ve yönetmeliklerde belirlenen görev, yetki ve sorumluluklarına uygun hizmet sunması, idari amirinin yetkilerini kullanarak aldığı kararları benimsemesi, etik yönden yaşanan sıkıntılarda etik karar verme sürecini izlemesi önerilmektedir.

\section{Çıkar çatışması}

Yazarlar arasında çıkar çatışması yoktur.

\section{KAYNAKLAR}

1. Uysal, H. (2010). Kardiyak arrest ve hemşirelik bakımı. Kardiyovasküler Hemşirelik Dergisi, 1(1), 19-27.

2. Perkins, G. D., Olasveengen, T. M., Maconochie, I., Soar, J., Wyllie, J., Greif, R., et al. (2018). European resuscitation council guidelines for resuscitation: 2017 update. Resuscitation, 123, 43-50.

3. Akbulut, E., Tülüce, D., \& Kahraman, B.B. (2016). Kardiyak rehabilitasyonda hemşirenin rolü. Journal of Cardiovascular Nursing, 7(14), 140-146.

4. Global Status Report on Noncommunicable Diseases 2014, WHO, http://apps.who.int/iris/ bitstream/10665/148114/1/9789241564854_eng.pdf?ua=1 (Erişim tarihi: 14 Ocak 2015)

5. Meaney, P.A., Bobrow, B.J., Mancini, M.E., Christenson, J., de Caen, A.R., Bhanji, F., et al. (2013). Cardiopulmonary resuscitation quality: Improving cardiac resuscitation outcomes both inside and outside the hospital. Circulation, 128, 417-435.

6. Türkiye Ulusal İstatistik Kurumu. Temel İstatistik. http://www.tuik.gov.tr/UstMenu.do?metod=temelist (Erişim Tarihi: 25 Aralık 2019).

7. Özköse, Z. (2005). Erişkinler için kardiyopulmonary resüsitasyon: I-Temel yaşam desteği. Gazi Tip Dergisi, 16, 3-13.

8. Günaydın, B. (2005). Pharmacotherapy in cardiopulmonary resuscitation. Turk J Med Sci, 35, 357-364.

9. Balc1, B., Keskin, Ö., \& Karabağ, Y. (2011). Kardiyopulmoner resusitasyon. Kafkas $J$ Med Sci, 1(1), 41-46.

10. Taş, D., \& Akyol, A. (2017). Kardiyopulmoner resusitasyon eğitiminde yeni eğilim: yüksek-güvenirlikli simulasyon. Journal of Cardiovascular Nursing, 8(17), 100-108. 
11. Cunningham, L.M., Mattu, A., O’Connor, R.E., Brady, W.J. (2012). Cardiopulmonary resuscitation for cardiac arrest: The importance of uninterrupted chest compressions in cardiac arrest resuscitation. Am J Emerg Med, 30(8), 1630-1638.

12. Ok, O., Vatansever, K., Araz, E.Ş., \& Ergün, V. (2016). Hastane öncesi kardiyopulmoner resusitasyon uygulamasında gögüs kompresyonu kalitesinin geliştirilmesi, Türkiye Klinikleri J Arrest Reanim, 14(3), 69-77.

13. T.C. Resmi Gazete. Sağlıkta Kalitenin Geliştirilmesi ve Değerlendirilmesine Dair Yönetmelik. https://dosyamerkez.saglik.gov.tr/Eklenti/3570,yonetmelikpdf.pdf?0 (Erişim Tarihi: 25 Aralık 2019).

14. Foster IR., Lasser FJ. (2015). Professional ethics in midwifery practice. Nermin E., Müesser Ö., Ayla E. Etik düşünce, bakım ve karar verme (s. 181-205). Ankara: Nobel.

15. Burkhardt, A.M., Nathaniel, A.K. (2013). Çăğdaş hemşirelikte etik. İstanbul: Medikal

16. Yönt G. (2015). Hemşirelikte etik karar verme. Çağatay Ü., hemşirelikte etik karar verme 1th ed. (s 53-64). İzmir: Ege

17. T.C. Resmi Gazete. Hasta Hakları Yönetmeliği. https://www.saglik.gov.tr/TR,10461/hasta-haklari-yonetmeligi.html (Erişim Tarihi: 25 Aralık 2019).

18. Türk Tabipler Birliği Merkez Konseyi. (1999). Hekimlik meslek etiği kuralları, Ankara,

19. T.C. Resmi Gazete. Sağlık Meslek Mensupları ile Sağlık Hizmetlerinde Çalışan Diğer Meslek Mensuplarının İş ve Görev Tanımlarına Dair Yönetmelik. https://www.resmigazete.gov.tr/eskiler/2014/05/20140522-14.htm (Erişim Tarihi: 25 Aralik 2019).

20. T.C. Resmi Gazete. Acil Sağlık Hizmetleri Yönetmeliği. https://www.saglik.gov.tr/TR, 10438/acil-saglik-hizmetleri-yonetmeligi.html (Erişim Tarihi: 25 Aralık 2019)

21. Türk Tabipler Birliği Merkez Konseyi. Hekimlik meslek etiği kuralları. https://www.ttb.org.tr/mevzuat/index.php?option=com_content\&task=view\&id=65\&It

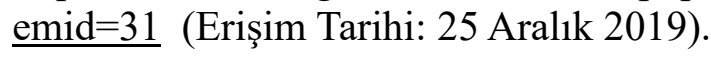

